\title{
青函航路に於ける波浪による横摇水の研究（続）
}

\section{A Study of the Wave-Induced Rolling Motion of a Ship in a Seaway (partII)}

\section{川 島 利 兵 衛 (北大水産学部)}

\begin{abstract} course, when ship was underway at 15 knots. obtained by use of the following ecuation:

$$
\begin{gathered}
\theta_{m a x}=-D_{W} \pm \sqrt{D_{W}-\left(2 \theta_{w} D_{W}-S_{d} / 0.8\right)} / m x \\
\theta_{m z x}: \text { Critical angle of roll } \\
\theta_{r}: \text { Range of stability } \\
D_{W} \quad: \text { Lever by wind pressure } \\
S_{d} \quad: \text { Dynamical stability } \\
m_{x} \quad: \text { Transverse metacentric height }
\end{gathered}
$$
\end{abstract}

In the former paper, the author considered the ship's rolling motion in a seaway from view point of forecasting ship's motions on the sea. In that paper, in the case of SEIKAN ferry boat, the maximum angle of roll of ship in the seaway was shown for various wind veocities ard 8 priccipal directions on standard

In this paper, from the foint of view of safety for the ship's stability, the author has defined the critical anlge of : oll due to wave motions, which was decided by the stability standard of sea-going ship, that critical angle can be

Then, under any sea states and wind conditions, it is necessary to manueover the ship to satisfy the following equation for the safety of ship.

$$
\begin{aligned}
& \theta_{m a x}: \stackrel{\theta_{W}}{>} \\
& \theta_{W}: \text { Relative angle of roll }
\end{aligned}
$$

And the relation between $\theta_{w}$ and maximum angle of roll is given as follows:

$$
\begin{aligned}
& \theta_{W}=\varphi-\psi^{\prime} \cos \phi \\
& \varphi: \text { Maximum angle of the seaway (Appendix 2) } \\
& \psi^{\prime}: \text { Effective wave s'ope } \\
& \phi: \text { Phase angle (between ship's motion and wave motion) }
\end{aligned}
$$

According to the akove theory, the author calculated $\theta \mathrm{w}$ on the standard course for the same conditions as in his former paper and discussed the matter of the safety of a ship in the seaway.

\section{1. 緒論}

著者は前論文 ${ }^{1}$ に於て、海上に於ける船の運動の研究を航海者の立場から船の動摇予報の問題 として、特に青函航路に於ける連絡船の横摇孔の研究をした。 
本諭交は於ては、更に得原性曲線に上る安全性の判定の力洁の立場から青函航路に於て波に上

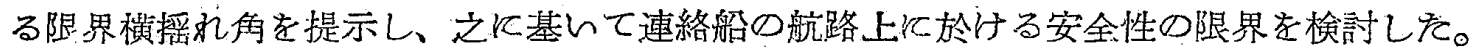

その方法として、(1)航路に於ける横摇れ角 (2)波浪による限界横摇れ的 (3)航路に於ける連絡 船の安全性 に就いて研究したが、(1)項に就いては前諭文に述べをが之を要約するとi)青函航路 の連絡船の指定針路に従つて計算の基準となる針路を定め、之に対して 8 点方位に就いての連吹 距離飞求めて、風速、夫ァ $10^{\mathrm{m}} / \mathrm{scc} 、 20^{\mathrm{m}} / \mathrm{scc}$ 、及び $30^{\mathrm{m}} / \mathrm{scc}$ 亿対して定常状態に達した場合の波高 及び波周期を算定した。 ${ }^{2)}$ 次に ii) 連絡船（洞爺丸型）につんて、動摇試験及び模型実験の結果 から横搯れ減裹係数、横摇れ固有周期及び有効波傾斜係数計算し、i）項で定つを波を規則波 として、横摇れの運動方程式の強制外力項として解き、强制横摇れの最大角と $\Lambda_{e}$ との関係を求 めた。iii）基準針路上のへeにつんて、i）項で求められた波高及び周期に基き連絡船の速度を 15 Knots として各風速及び風问に対する $\wedge_{e}$ 昰求めた。(Fig 3.2、Fig 4-2)

以上飞従つて、航路上のある点に於ける風向、及び風速が分るとその点の波浪予報伴つて、 i） ii）及び (ii) より横摇れの最大角が分る。

従つて、前論文にも述べを様に、復原性曲線による安全性の判定する立昜からの教察によつて この横摇れ最大角を吟味すれば、連絡船の航路上《於ける危険性の予報が可能であると考えられ る。

\section{2. . 波泿による限界横摇れ角}

船の復原性に関する問題に於て、安全性に就んてはGMの大をさで決められる方法と復原性曲 線で判断する方法が採られているが海上に於ては更に、突風、波浪等の動力学的を考察を加える 必要がある、この見地から復原性の安全示数 ${ }^{4)}$ が提策され; 最近の研究に於いては、海洋上の風

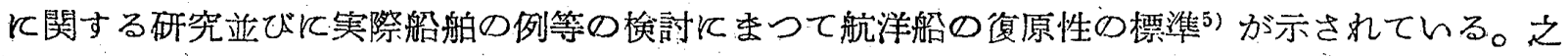
Кよると、

$$
\frac{S_{d}}{D_{W}\left(2 \theta_{r}+\theta_{o}\right)+\frac{m_{x}}{2} \theta_{o^{2}}}>0.8 \quad \frac{S_{a}}{\left(D_{W}+D_{W}^{\prime}\right) \theta_{r}}>0.8
$$

$$
\begin{aligned}
& \mathrm{S}_{a}=\text { 動的復原力、 } \theta_{r}=\text { 復原性範囲 } \\
& \mathrm{m}_{x}=\text { メタセンター一䯩、 } \mathrm{D}_{w}=\text { 風圧挻 }
\end{aligned}
$$

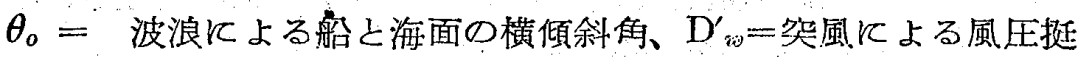

(1)式飞於て波浪による影響のみを考元ると即ち、(i)式を $\theta_{0}$ K就んての不等式として解くよ、

$$
\theta_{m i n}<\theta_{0}<\theta_{m i x}
$$

$\theta_{\text {max }}$ につんては、次式によつて与えられ波浪に上る限界横摇れ角上する。叉 $\theta_{\text {min }}$ につんん ては安全性の点から考察を要しなん。

$$
\theta_{m a x}=\frac{-D_{W}+\sqrt{D_{W}{ }^{2}-4 \cdot\left(2 \theta_{r} D_{W}-S_{a} / 0.8\right)}}{m_{x}}
$$

従つて船の航路に於んて波浪による横摇れ解 を $\theta_{W}$ とすれば、(2)式により

$$
\theta_{W}<\theta_{\max }
$$

但し、 $\theta_{W}$ 船上波面之の相対倾斜角なること が復原性曲線から見て船の安全性の必要条件で ある。航路に於ける船の安全運航を遂行する為 には波に対しては(4)式を満足する滕に操船しは ければならない。

Fig. 1. Stability Curve for TOYA MARU Disp. 5,120 tons , Mean draft $4.805 \mathrm{~m}$

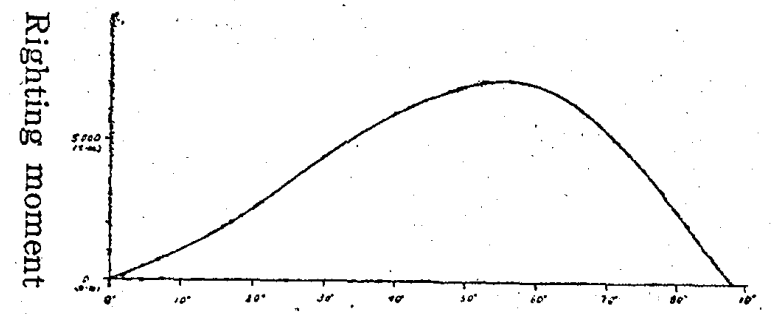

Angle of inclination (deg) 


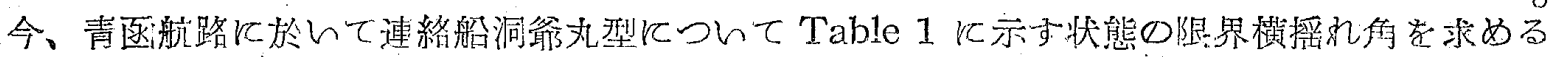

i ) 動的復原力 $\left(\mathrm{S}_{a}\right)$ 项び復原性範团 $\left(\theta_{r}\right)$

Table 1 につんて、車轌甲板後端か潤放されてんる量合、浮力に算入される渻国は上部遊步甲

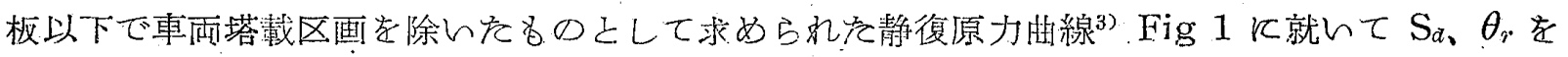
求め\%。

$$
S_{a}=69.12 m \operatorname{mog} \quad \theta_{r}=88 \text { 。 }
$$

ii）属圧挺 $D_{W}$

風王挺の算定には次式に従つた。

$\mathrm{D}_{w}=0.78 \times 10^{-4} \mathrm{CAlv}^{2} \sin ^{2} \alpha / w$

$\mathrm{C}=$ 風圧係数 $\quad \mathrm{C}=0.75 。 \overline{\mathrm{OG}}^{0.21}$

$\overline{\mathrm{OG}}=$ 水線上風圧中心迄の距離 $(\mathrm{m})$

$\mathrm{A}=$ 風圧面積 $\left(\mathrm{m}^{2}\right)$ 、重淔浮泛時:の水線上部分の投影面積

$\mathrm{v}=$ 相対風速、 $\alpha=$ 相対風向

Table 1 C condition Кつんては、

$$
\begin{array}{lll}
A=1,279\left(\mathrm{~m}^{2}\right) & \mathrm{OG}=6.050(\mathrm{~m}), \text { 突 } \\
1=8.460(\mathrm{~m}) & \mathrm{C}=1.095 & \text { 岁 }
\end{array}
$$

相対性風速は風向につんては、船の速力 $15 \mathrm{Knots}$ と乙て緒論と同様に、真針路 $00^{\circ}$ $180^{\circ}$ とし風向真方位 $45^{\circ} 、 90^{\circ}$ 及び $135^{\circ}$ に対して風速 $10^{\mathrm{m}} / \mathrm{scc} \sim 60^{\mathrm{m}} / \mathrm{scc}$. に就いて 計算した。 Talle2. 3

iii) $\theta_{m a x}$ ○算定

Fig. 2. Critical Angle of roll due to Wave motions.

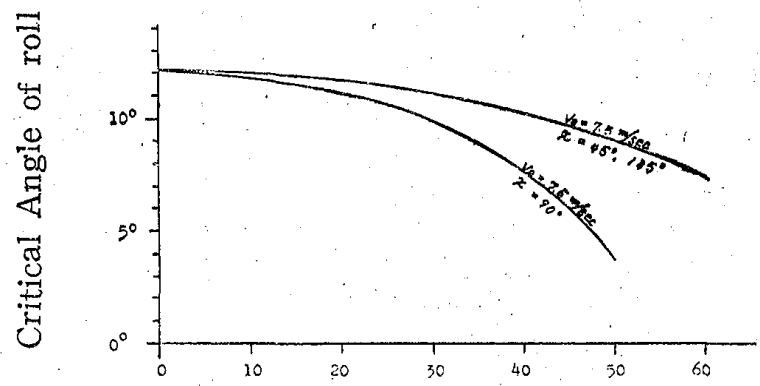

Wind velocity $(\mathrm{m} / \mathrm{sec}$.

(3)式に従つて各、 $\mathrm{D}_{w}$ とつんて $\theta_{\operatorname{man}}$ 它計算して風速槛座標として表はすと、Fig.2 となる。 計算の結果に上れば風向 $45^{\circ}$ 及び $135^{\circ}$ の昜合 $\theta_{\text {man }}$ 曲線に殆んで一致する、又 $90^{\circ}$ 亿於て は、船速 15Knots の場合亡停止の昜合亡殆ん,゙一致する。

\section{3. 航路に於ける波泿による最大横摇れ角よ限界横摇れ角について}

緒論、及び appendix に述べられを最大横摇れ每は絶対横摇れ角（即ち絶対座標を基準とし ている)であるが、傾斜角は船と海面のなす相対傾斜角であるから、航路に於ける最大横摇れ角

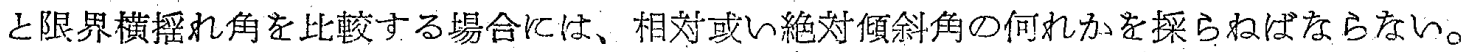

從つて、前節で述べられを最大横摇れ角と波浪による船の海面上のなす最大横浪れ角 $\theta_{W}$ とし て表はすと、

$$
\theta_{W}=\phi_{m a x} \sin w_{e} t-\psi \sin \left(w_{e} t-\phi\right)
$$

$\phi m a x=$ 波浪に上る最大横浪れ角（絶対座標）

$w e=$ 船亡波との出会の角振動数

$\psi^{\prime}=$ 波の有効傾斜角

$\phi=$ 船亡波の運動の位相差

$$
\phi=\tan ^{-1} \frac{2 \mathrm{k} \wedge e}{1-\wedge^{2}{ }_{e}}
$$

最大傾斜の昜合につんては、 $w_{e} t=\frac{\pi}{2}$ 又は $n \pi t \frac{\pi}{2} n$ : 整数であるから上式より、

$$
\theta_{W}=\phi_{m a x}-\psi^{\prime} \cos \phi
$$


亡なる。

従つて前論文に続き、復原性曲線よりの安全性の観点から青函航路に於ける波浪による横摇れ を教察するととが出来る。

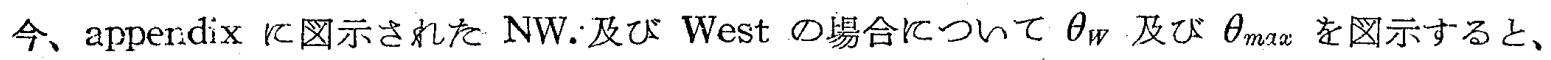
Figs. 3-4 之なる。但し、 $\theta_{W}$ 算定につんての諸計算は本論文には省略する。
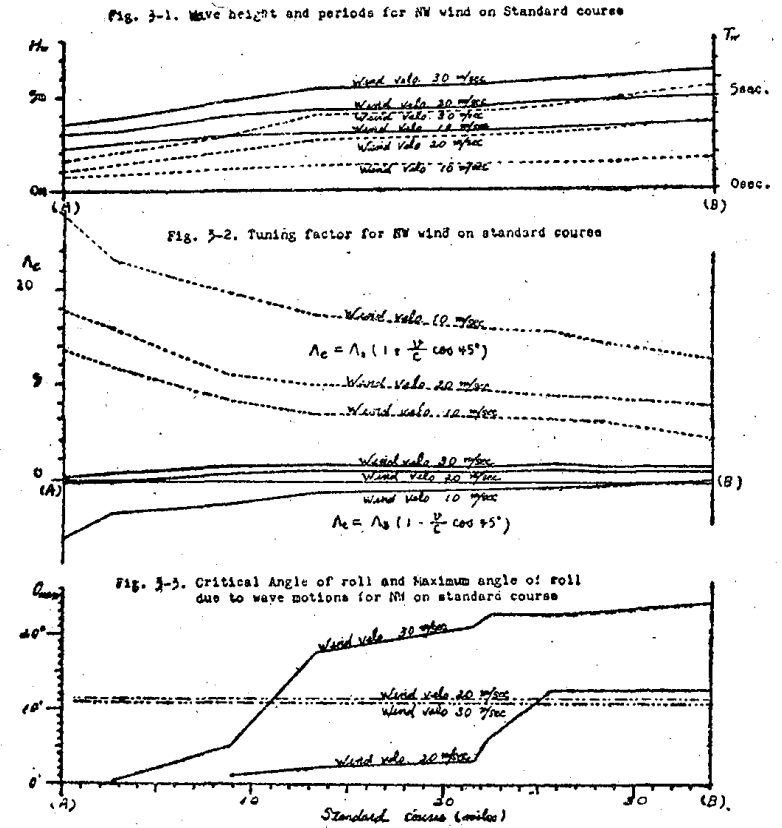
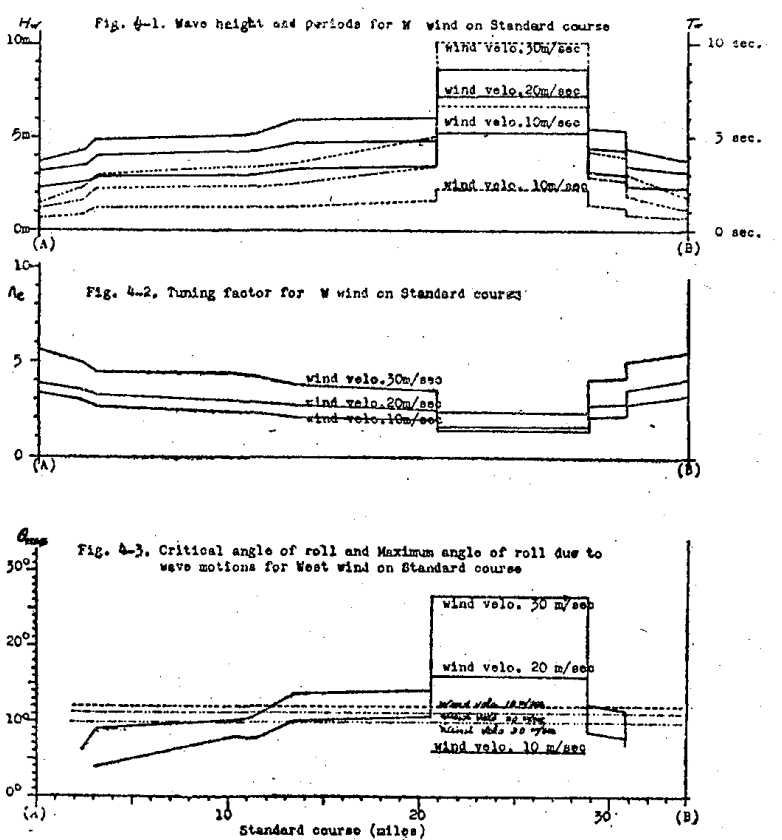

\section{4. 考察}

連絡船洞爺北型が 15Krots の速力で基準針路を航行すると、各風速に対する波浪による海

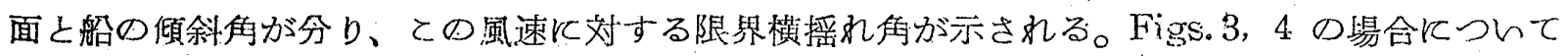
見る之、完全性の必要条件を $\theta_{m}<\theta_{m x x}$ として考えると二つの場合がある。

i ）連吹巨離の長い場合には、風速 $20 \mathrm{~m} / \mathrm{sec}$ K於て子 $\theta_{W}>\theta_{\max }$ 亡存る。 Fig. 4

ii）連吹距離が比較的短い昜合飞は、Tuning factor $\Lambda \mathrm{e}=1$ のときは $\theta_{W}>\theta_{\max }$ になるとと が Fig. 3 と示されている。

Fig. 3 K就いては、船と波との出合角度 $x=45^{\circ}$ の踼合、即ち波を横後に受けてんる場合で あつて、艄方向からの昜合には (4)式の $\theta_{W}<\theta_{\text {max }}$ の条件は充分淽足され従つて管全である。

以上の方法はよつて青函航路に就いて所要の航路上の点に対して危除となるべき気象条件が推 定され得る、又所要の気象条件が充分られれば航路上の任意の点の安全性の検討が可能亡存る。

但し、本論文では、連絡船の風圧による速度低下或は強風による操従性の低下につんては考え ていない。又波浪の算定に関しては前論文と同じ条件を用んている。

最後に、本論文飞於亡は、特飞、日本海事検定協会、佐藤正彥氏に上る “青函連絡船洞爺文等 の復原性鑑定につんて”に於ける data を用んたことにつんて、同氏に深謝する。

\section{交献}

1) 川島、(1955)青函航路に於ける波浪による横摇れの研究

北大水産学部研究量報、第 6 巻、第 3 号 $216-227 \mathrm{P}$

2) Sverdrup, H. U: \& Munk, W.H. (1917) Wind, sea and swell ; theory of relation fore- 
forecasting 37P. H. O. pul. 601

3）佐藤正㝘 (1955) 青函連絡船洞爺丸等の復原性㘕定に ついて 日本海事協会々誌第34号校刷

4 ) 渡辺恵弘 (1947) 船舶の復原性より冒たる安全示数 造船協会及報 (79) 9-21P

5 ）渡辺恵弘、山上直人、井上正裕、真鍋大覚 (1955)

The stability-standard of seagoimg ships 造船塐 会論交集 97 号

Appendix 1

青函航路に於忬る基隻針路 Fig. A-1

基準針路に基いて算定された連吹距離 Fig. A-2

Fig. A-2.に基いて計算された波䯩及び波周期

Fig.3-1, Fig.4-1

Appcndix 2

Ae と最大横摇れ刍 $\varphi$ max の関係 Fig.A-3
Fig A-1 Standard cource in SEIKAN KCRO

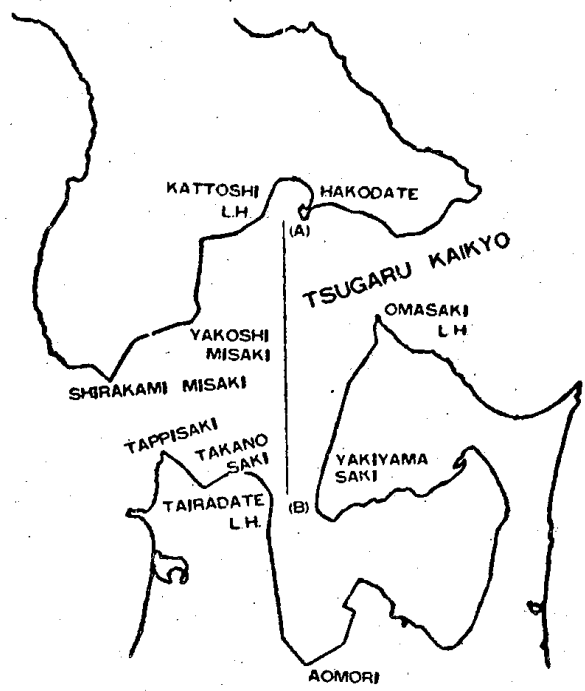

(A) Kattoshi LII $2 . ' 5$ off (B) Tairadate LHI $2 .^{\circ} 0$ off

Fig. A-2 Fetch on the stardard course in Fig. A-1, for 8 principal dircction

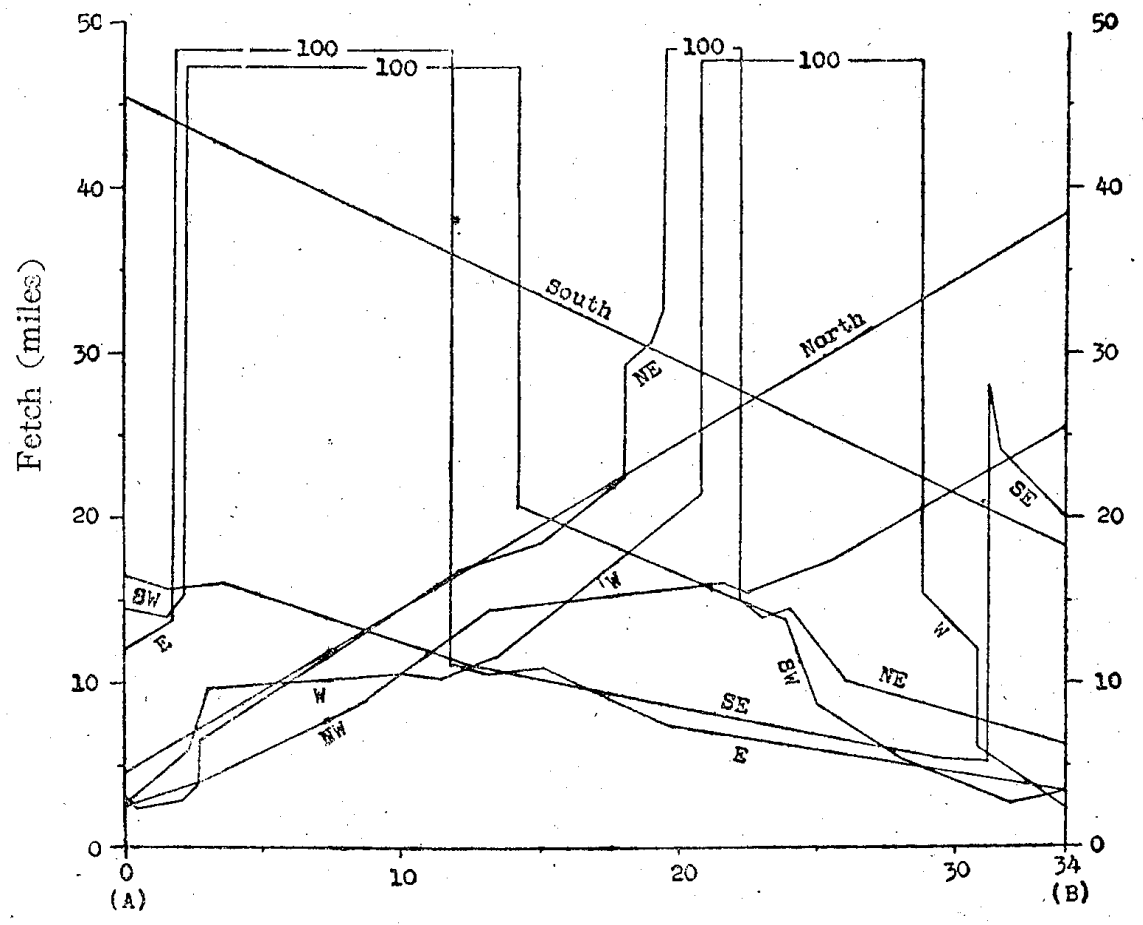

Distance on standard course (miles)

Table 1.

L $113.2 \mathrm{~m}$

B $15.58 \mathrm{~m}$

D $6.80 \mathrm{~m}$

Disp.

5,120 tons

Fore

4. $556 \mathrm{~m}$

Draft.Aft

5. $053 \mathrm{~m}$

Mean

4. $805 \mathrm{~m}$

GM

$1.198 \mathrm{~m}$

Rolling period 12.5 sec. 
Fig. A-3 The Relation between roll angle and effective tuning facctor

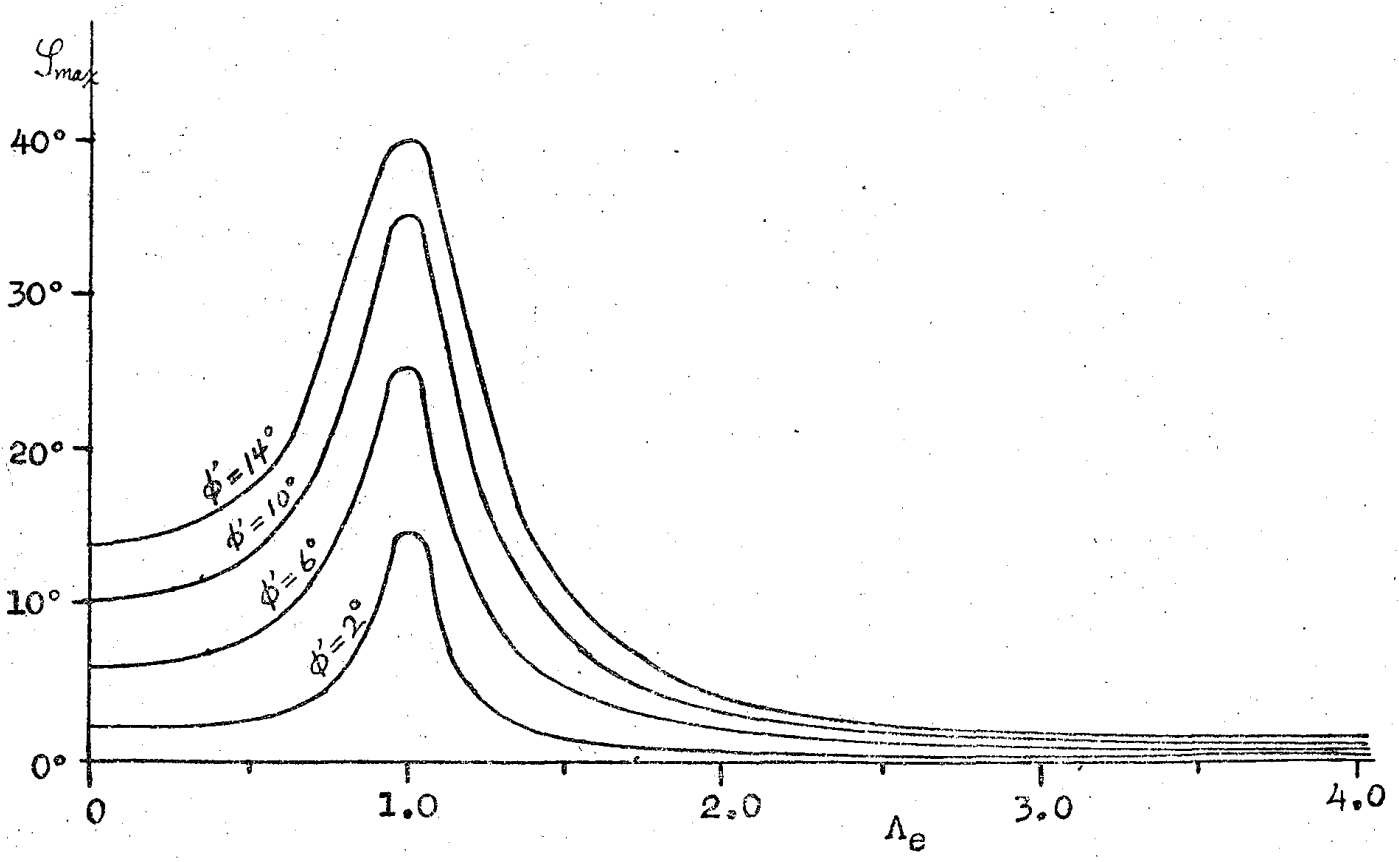

Table 2.

Wind velo. $\quad 10 \mathrm{~m} / \mathrm{s} \quad 20 \mathrm{~m} / \mathrm{s} . \quad 30 \mathrm{~m} / \mathrm{s} \quad 40 \mathrm{~m} / \mathrm{s} \quad 50 \mathrm{~m} / \mathrm{s} \quad 60 \mathrm{~m} / \mathrm{s}$ Wind Dir. (T)

$33.5^{\circ}$

$37.0^{\circ}$

$38.0^{\circ}$

$39.2^{\circ}$

$40.5^{\circ}$

$90^{\circ}$

R.V. $16.1 \mathrm{~m}$

$25.7 \mathrm{~m}$

$35.3 \mathrm{~m}$

$45.7 \mathrm{~m}$

$55.5 \mathrm{~m}$

$64.0 \mathrm{~m}$

R.D. $59.2^{\circ}$

$59.5^{\circ}$

$67.0^{\circ}$

$79.2^{\circ}$

$81.4^{\circ}$

$82.5^{\circ}$

$135^{\circ}$

R.D. $86.5^{\circ}$

$114.8^{\circ}$

$40.9 \mathrm{~m}$

$50.8 \mathrm{~m}$

$60.6 \mathrm{~m}$

R.V. $7.0 \mathrm{~m} \quad 15.5 \mathrm{~m}$

$122.2^{\circ}$

$141.5^{\circ}$

$140.0^{\circ}$

$139.3^{\circ}$

R.D. : Relative wind direction (T)

R.V. : Relative wind velocity (m/sec.)

Table 3.

Wind velo. $\quad 10 \mathrm{~m} / \mathrm{s} \quad 20 \mathrm{~m} / \mathrm{s} \quad 30 \mathrm{~m} / \mathrm{s} \quad 40 \mathrm{~m} / \mathrm{s} \quad 50 \mathrm{~m} / \mathrm{s} \quad 60 \mathrm{~m} / \mathrm{s}$ Wind dir. ( $T$ ) Dw
$45^{\circ}$
0.0087
0.0363
0.0833
0.1428
0.2220
0.3118
$90^{\circ}$
0.0211
0.0732
0.1640
0.2913
0.4553
0.6514
$135^{\circ}$
0.0088
0.0363
0.0814
0.1361
0.2144
0.3114 